\section{Caminos transversales por el interior de la provincia de Buenos Aires: el Plan Vial 1959-1963}

Alejandra Laura Salomón

CONICET / Centro de Estudios de la Argentina Rural, Universidad Nacional de Quilmes, Argentina.

Recibido: 31 de enero de 2019. Aceptado: 22 de mayo de 2019.

\title{
Resumen
}

A mediados del siglo XX, en medio del auge del desarrollismo, en ámbitos gubernamentales y técnicos comenzó a enfatizarse la necesidad de descentralización vial para generar fuentes de riqueza y revertir la concentración poblacional, económica y política de la provincia de Buenos Aires. Este pensamiento quedó reflejado en el Plan Vial 19591963 que, diseñado bajo la gobernación de Oscar Alende, previó el trazado transversal de nuevas rutas y el mejoramiento de las existentes. En este marco, el trabajo aborda -con fuentes estatales, publicaciones periódicas e informes técnicos- el significado y el alcance de una política pública que, al tiempo que valorizaba el territorio local, intentaba revertir la asimetría regional. Para ello se examinará sucesivamente la problemática que llevó a la formulación del Plan Vial, las concepciones subyacentes y el esquema propuesto. La hipótesis de trabajo es que la particular modalidad de intervención estatal en materia vial abrevaba en los postulados desarrollistas que promovían el rol decisivo del Estado en la provisión de infraestructura, así como la descentralización, la planificación y la iniciativa privada como pilares de la modernización del sector agrario.

\section{Transversal routes in the interior of the province of Buenos Aires: the Road Plan 1959-1963}

\begin{abstract}
Abstact
In the mid-20 th century, in the midst of the boom of developmentalism, in governmental and technical fields began to emphasized the need for decentralization road to generate sources of wealth and reverse the population, economic and political concentration of the province of Buenos Aires. This thought was reflected in the Road Plan 1959-1963, which, designed under Oscar Alende `s government, projected new transversal routes and the improvement of existing ones. In this framework, the work analyzes -with state sources, press and technical reports- the meaning and scope of a public policy that, while valuing the local territory, tried to reverse the regional asymmetry.
\end{abstract}

Palabras clave

Política vial Desarrollismo Rural Provincia de Buenos Aires

\section{Palavras chave}

Política rodoviária Desenvolvimentismo Rural Província de Buenos Aires

\section{Keywords}

Road policy Developmentalism Rural

Province of Buenos Aires 
For this, the problems that led to the formulation of the Road Plan, the concepts and the proposed scheme will be examined. The hypothesis is that the particular modality of state intervention in road matters was influenced by the developmental ideas. These ideas promoted the decisive role of the State in the provision of infrastructure, as well as decentralization, planification and private initiative as pillars of the modernization of the agricultural sector.

\section{Introducción}

A mediados del siglo XX, en una coyuntura signada por las expectativas en torno al desarrollo, en ámbitos gubernamentales y técnicos comenzó a enfatizarse la necesidad de descentralización vial como vía para generar nuevas fuentes de riqueza y revertir la concentración poblacional, económica y política de la provincia de Buenos Aires. Este pensamiento quedó reflejado en el Plan Vial 1959-1963, diseñado bajo una gobernación -de Oscar Alende- que manifestó a su vez una singular preocupación por la cuestión agraria. Dicho Plan previó el trazado transversal de nuevas rutas y el mejoramiento de las existentes en pos del desarrollo del interior de la provincia (es decir, fuera del área metropolitana).

En la Argentina, no abundan los trabajos sobre vialidad, y la mayor parte de ellos se dedican a la primera mitad del siglo XX (entre otros, Ballent, 2005 y 2008; Ospital, 2002; Gruschetsky, 2012; Gómez y Tchordonkian, 2014; Piglia, 2011 y 2014; Fernández, 2016). Desde distintos enfoques teórico-metodológicos y áreas específicas de interés, todos ellos reconocen en los años treinta una intensa y decidida intervención del Estado en materia vial, asociada al proceso de urbanización, la difusión del automóvil, la presión de intereses sectoriales (como el Automóvil Club Argentino, el Touring Club Argentino y los importadores de automóviles), el accionar de los ingenieros en las reparticiones estatales y la expansión del turismo. La sanción de la Ley Nacional de Vialidad en 1932, al crear un organismo autárquico (la Dirección Nacional de Vialidad, en adelante DNV), proveyó en forma regular y permanente fondos para la construcción de carreteras y estableció un sistema de ayuda federal a las provincias, permitiendo la formulación de planes de largo alcance. Se inició así una intensa labor estatal que, concebida como moderna, eficiente, centralizada y apolítica, a mediados de la década siguiente empezó a declinar. Por entonces, las nuevas y poderosas representaciones mostraban el sistema a diseñar como una trama, y no un abanico, como ocurría con el trazado de los ferrocarriles (Ballent, 2005:116). Estas imágenes, asociadas también a la racionalidad técnica, la planificación, la integración territorial y al patriotismo, operaron en la construcción de la tan ansiada red nacional de caminos permanentes, la cual tendía a confluir en el mojón que en la Plaza del Congreso indicaba el "kilómetro cero". En términos simbólicos, integrar el territorio a través de la obra vial implicaba fundamentalmente modernizar el medio rural (acercándolo a las urbes), fomentar el comercio y estimular la recreación de los sectores urbanos. Dicha interpretación formaba parte de un contexto intelectual que valoraba tanto el crecimiento de la población urbana como la funcionalidad económica del campo en tanto garantía para el progreso. De allí que los múltiples emprendimientos de aquellos años subrayaban la primacía de las rutas que oficiaran como soporte del transporte de la producción agraria con destino al puerto de Buenos Aires, así como del turismo. Por lo tanto, y a pesar de los avances, en la práctica siguió preponderando el esquema radial con epicentro en la capital nacional.

El ascenso de Juan Domingo Perón a la presidencia, en 1946, habría significado una continuidad en materia vial (Gómez y Tchordonkian, 2014:22), pese a la pérdida de autarquía de la repartición y a las dificultades para adecuar limitados recursos a 
un escenario más complejo. Las expectativas en torno a las carreteras de bajo costo expresaban que el transporte de la producción agropecuaria, el turismo y la defensa constituían los objetivos prioritarios. Las estadísticas muestran que las construcciones proyectadas y realizadas fueron significativamente menores, aunque dentro del plan de obras públicas, las viales contaron con cuantiosas inversiones. Por su parte, el mapa del sistema caminero de la etapa peronista permite observar la profundización de una tendencia inaugurada tibiamente en la década anterior: la interconexión, que modificaba lenta y parcialmente el tradicional esquema radial. Pese a ello, el centro de gravitación de la acción vial siguió desarrollándose en las ciudades o centros económicamente relevantes, quedando excluidos aquellos espacios del interior escasamente rentables. Las condiciones de vida rurales no estaban inscriptas en el mapa de poder político, no constituían un tema forjador de imágenes alrededor del camino, es decir, un problema socialmente problematizado (Salomón, 2017).

Ahora bien, ¿qué sucedió con la política vial y sus representaciones durante la segunda mitad del siglo XX? Aunque relevantes, los aportes historiográficos han sido escasos (Iramain, 2013; Civitaressi, 2018), en tanto que sobre la provincia de Buenos Aires en tiempos del gobierno de Alende la incursión fue tangencial. Se ha señalado que los programas vial, energético y agrario manifestaban una preocupación gubernamental por la deformación y el subdesarrollo de la economía bonaerense. Las máximas autoridades provinciales coincidían en un diagnóstico: la inequitativa distribución de la propiedad territorial era la principal responsable de desigualdades sociales en el ámbito agrario (Lázzaro, 2008:102). Si bien la cuestión de la tierra se posicionaba en el centro del debate público, otras propuestas en beneficio de la vida cotidiana de los sujetos rurales alcanzaron por entonces cierta visibilidad, tal como ocurrió con la construcción de centros de salud y educación, mejoras salariales, acceso a la ciencia y a la técnica e infraestructura básica (caminos, electricidad, agua potable), las respuestas se destacaron por su inconsistencia y su falta de sustentabilidad en el tiempo (Ivickas, 2017:643).

En este marco, el trabajo explora una dimensión que no ha sido muy atendida por la historiografía, como es la infraestructura vial en el interior de la provincia de Buenos Aires en tiempos de política desarrollista. Aspira a demostrar que las políticas viales de mediados del siglo XX marcaron un hito, por su significado y su alcance, puesto que, al tiempo que valorizaban el territorio local, intentaban revertir la asimetría regional simbolizada en la distribución de rutas en forma de abanico convergente a la Capital Federal. Para ello se examinará sucesivamente la problemática que llevó a la formulación del Plan Vial 1959-1963, las concepciones subyacentes y el esquema propuesto. Como para estudiar una política pública hay que contextualizarla, primero reconstruiremos las transformaciones socio-económicas y la situación vial en el interior de la provincia de Buenos Aires a mediados del siglo XX. Luego tomaremos a las ideas como una de las variables explicativas para, finalmente, examinar el significado del Plan Vial. Documentación estatal, publicaciones periódicas e informes técnicos oficiarán como fuentes para rastrear las transformaciones materiales y simbólicas que condujeron a la formulación de tal iniciativa.

Este artículo introduce tanto elementos subjetivos -representaciones sociales (Raiter et al., 2002)-, como elementos más objetivos relativos al contexto y a los intereses de los sujetos, enfocándose en la génesis del Plan Vial y no en su implementación. Como plantea Muller (2002), estudiar la génesis de una política pública implica la formulación de dos preguntas fundamentales. La primera es su origen intelectual: ¿de qué corrientes de pensamiento es heredera? Lejos de representar un mero proceso de decisión, puede ser entendida como un cúmulo de imágenes de la realidad sobre la que se quiere actuar. Segundo, ¿qué transformaciones sociales y económicas motivan la intervención del Estado en una sociedad civil cada vez más compleja? ¿Qué procesos conducen a que un asunto se convierta en objeto de una política pública? En esta dirección, para este 
trabajo resulta un aporte la perspectiva de Oszlak y O'Donnell, para quienes las políticas estatales constituyen un conjunto de acciones y omisiones que manifiestan una determinada modalidad de intervención del Estado en relación con una cuestión que concita atención, interés o movilización de otros actores en la sociedad civil (Oszlak y O'Donnell, 1981). Es decir, interactúan con un proceso social tejido alrededor de temas que las originan y suponen una priorización de los mismos. La selección prioritaria compone la agenda pública, que nos muestra cuál es la percepción de los poderes públicos sobre lo que se debe atender y resolver (Tamayo Sáez, 1997).

En base a este marco teórico consideramos que, como toda política pública, el Plan Vial anida en una serie de procesos e imaginarios sobre el camino. A mediados del siglo XX, en el interior rural de la provincia de Buenos Aires, el desarrollo del sector automotriz, el incremento de los desplazamientos a las ciudades, la expansión agraria y la difusión de nuevas pautas de consumo que se asemejaban a las de los sectores medios urbanos generaron la necesidad de construir nuevos caminos y de mejorar y conservar adecuadamente los existentes. Estos fenómenos se vincularon con otros dos: el despoblamiento rural y la concentración en el área metropolitana. Frente a ellos no fue casual entonces que la política vial expresara el anhelo por mejorar la posición las poblaciones del interior de la provincia, teniendo en cuenta que aportaban una gran proporción de la producción agropecuaria del país y que podían ser potenciales focos industriales.

Por otro lado, y en base a la premisa de que las ideas y los saberes técnicos juegan un rol preponderante en el proceso y los cambios de las políticas (Sabatier, 2010), identificamos un vínculo entre desarrollismo y política vial. Pese a que la promesa de desarrollo e integración que la red caminera inspiraba no constituía un elemento inédito, sí lo eran las modalidades de intervención pública con que tales expectativas se sostenían a mediados del siglo XX. Dicha modalidad de intervención abrevaba en los postulados que promovían el rol decisivo del Estado en la provisión de infraestructura y en la reversión de los desequilibrios territoriales, así como la descentralización, la planificación y la iniciativa privada como pilares del desarrollo.

\section{El interior bonaerense: transformaciones socio-económicas y situación vial a mediados del siglo XX}

A mediados del siglo XX, aunque con ritmos diversos y heterogeneidades locales, se intensificaron una serie de transformaciones -algunas gestadas con anterioridad- que afectaron las condiciones de vida y de trabajo de los habitantes rurales del interior de la provincia de Buenos Aires. Un primer fenómeno significativo consistió en la recuperación agropecuaria, traccionada por nuevas inversiones y medidas favorables hacia el sector. Una vez derrocado el peronismo, una de las cuestiones centrales de la problemática agraria fue el relativo estancamiento de la producción, en especial, agrícola. Prueba de ello es que la superficie sembrada de avena, maíz y trigo -principales productos- estaba en 1960 a un nivel inferior al de 1947: 4.370.199 ha frente a 4.654.868 ha (Instituto Nacional de Estadísticas y Censos, 1947 y 1960). Lo mismo ocurría con los niveles cosechados, tendencia compensada por la leve expansión ganadera. Los guarismos indican que el stock vacuno pasó de 14.761 .486 cabezas en 1950 a 17.517 .793 en 1960, mientras que los ovinos se incrementaron de 12.746.462 a 19.044.463 (Ministerio de Hacienda, Economía y Previsión de la Provincia de Buenos Aires, 1952; Instituto Nacional de Estadísticas y Censos, 1960).

Frente a este panorama, la fuerte devaluación de 1955 resultó -al menos en el corto plazo- el salto más drástico, seguido de la disolución del IAPI, la liberación del precio 
de la carne, la fijación de un precio mínimo para los cereales, beneficios impositivos, créditos subsidiados y la derogación del congelamiento de los arrendamientos. La recomposición de incentivos al agro, tendencia que ya se vislumbraba desde finales del gobierno peronista, facilitó la obtención de recursos y comenzó a revertir la tendencia. Además, influyeron en la conducta de los productores los adelantos tecnológicos que, al tiempo que resolvían el problema de escasez de mano de obra y mejoraban la productividad, daban lugar a la expansión agrícola, inicialmente lenta (Barsky y Gelman, 2001:333). En paralelo, aumentó la producción lechera, se produjeron cambios en la actividad ganadera (asociados a la composición de razas, la introducción de nuevas técnicas frigoríficas y la propagación de praderas artificiales) y mantuvieron cierta relevancia las pocas industrias del interior de la provincia (Rougier, 2014:125). Por otra parte, el puerto de Buenos Aires concentraba la mayor parte del tráfico comercial. Mientras que en 1960 ingresaban a dicho puerto 1.943 embarcaciones, 113 lo hacían al puerto de Bahía Blanca, 156 a Rosario y 515 al resto de los puertos -Santa Fe, Necochea, La Plata, Puerto Madryn, etc.- (Cámara Argentina de la Construcción, s/f).

Otro de los hechos destacados del período fue la creación en 1956 del Instituto Nacional de Tecnología Agropecuaria (INTA), institución destinada a la tecnificación y al mejoramiento de la empresa agraria y de la vida rural, en un momento en que la cuestión tecnológica empezó a ser problematizada como la llave maestra para superar el estancamiento. Así fue cómo la actividad agropecuaria, junto a la industrial, se consolidó como el sector económico al cual los poderes públicos le asignaron objetivos de productividad ambiciosos con el fin de recuperar lo que por entonces se percibía como un retraso dramático.

La modernización del agro bonaerense trajo aparejado una importante mutación en la vida rural y en las relaciones con el espacio (Albadalejo, 2017). Muchos productores reemplazaron paulatinamente las labores físicas por las gerenciales, delineando un nuevo perfil que se definía como profesional y descalificaba el modo de vida rural. A su vez, la difusión de nuevas pautas de consumo que los asemejaban a los sectores medios urbanos, en combinación con la desvalorización de los productos elaborados por la propia familia o comunidad, los involucró cada vez más en el mercado. No sólo el deseo de bienes de consumo masivo, la participación de alguna actividad cultural o de esparcimiento, la visita al médico, el abastecimiento de insumos o la reparación de maquinarias más complejas incrementaron la frecuencia de los viajes a las ciudades (de una o dos veces al mes a dos o tres veces por semana), sino también motivaron el abandono de la explotación como residencia permanente (Balsa, 2006). Así, los pequeños pueblos dejaron de ser centros de la vida social agraria y las ciudades-cabecera de los distritos ocuparon su lugar como espacios de sociabilidad.

En los años sesenta, una encuesta a productores medios de la región pampeana detectó una tendencia a migrar a las localidades urbanas cercanas, sin abandonar la propiedad agraria ni su manejo inmediato (Brie, 1977:49). En otros casos, la migración de trabajadores fue permanente, debido a cambios productivos que derivaron en la disminución de mano de obra necesaria para las tareas agrícolas. Es menester tener en cuenta que la mayor disponibilidad y las innovaciones de los automóviles y la mejora de las grandes rutas pavimentadas habrían obrado a favor de estos fenómenos (Balsa, 2006).

De acuerdo a un estudio de la Dirección Provincial de Energía, durante el lapso comprendido entre 1950 y 1957 se registró un éxodo de 95.400 habitantes hacia el área metropolitana (Brie, 1977:23-24). ${ }^{1}$ La combinación de factores objetivos y subjetivos generó una dinámica de retroalimentación. El despoblamiento de los campos y el aislamiento concitaron preocupación, no sólo entre los residentes rurales sino también 
entre ingenieros agrónomos. No casualmente, la encuesta antes mencionada se encargó de medir la distancia al pueblo y entre vecinos (Brie, 1977:29-30). La distancia al centro urbano más próximo que predomina en el universo encuestado es la de 5-20 $\mathrm{km}(49,7 \%)$, seguida por 20-40 km (19,6\%), 1-5 km (13,5\%) y más de $40 \mathrm{~km}(6,1 \%)$; el 10,9\% habitaba dentro del pueblo. En tanto, el $40 \%$ de las familias distaba $1 \mathrm{~km}$ del vecino más cercano. La distancia aparecía así como un condicionante que operaba en el tiempo y el espacio, incidiendo en las pautas culturales (aspiraciones, formas de vida, uso del tiempo, ocio, información, etc.), el empleo de los instrumentos de la modernidad (medios de comunicación social, tecnología, etc.), el acceso a bienes y servicios típicamente urbanos (mayor desarrollo de la educación, de la salud, etc.) y las decisiones (por mayor contacto con los centros de decisión y con las organizaciones de base). Este esquema interpretativo que estima la cercanía física entre los individuos se condice con otras valoraciones de la época: el confort, la activa vida social y cultural, así como la promisión de oportunidades y la modernidad que ofrecían las ciudades. Si bien la sobreestimación de estas últimas no resulta novedosa -ya desde el siglo anterior se las caratulaba como la garantía para el avance del progreso y la civilización-, fue el contexto de mediados del siglo XX el que reforzó su atractivo. Aunque, sin dudas, la realidad mostró fuertes contrastes y desilusiones.

Las fuentes locales dejan entrever una interpretación de las migraciones internas no comandada exclusivamente por factores de atracción imperantes en las zonas de llegada, sino también por factores de expulsión. El denominador común de la armazón explicativa por parte de la prensa lugareña se refería a las condiciones críticas del lugar de origen; visión que, desde luego, suponía un llamado de atención a las autoridades. Un ejemplo respalda esta afirmación. Siguiendo la preocupación dominante por el éxodo rural, el periódico pergaminense El Tiempo alertaba en su editorial sobre los perjuicios del aislamiento:

La vida en los pueblos de campaña es monótona, aburrida, desesperante. Y no porque sus habitantes se aíslen socialmente o sean muy individualistas (...) Lo que necesitan esos vecindarios es el intercambio (...) Andar y ver, como se hace en los centros urbanos. Muchas localidades quedan aisladas desde el atardecer hasta el otro día, sin comunicación terrestre, telefónica o ferroviaria. Y sin luz (...) Lo que en realidad falta es (...) buenos caminos, servicios de trenes y transporte de pasajeros más frecuentes (...). Los pueblos de campaña debieran estar conectados todos con los centros urbanos más próximos con caminos transitables y seguros en todo tiempo y entrar en su recinto el beneficio del pavimento. El automóvil y el colectivo harían el resto y entonces se iría eliminando el éxodo rural (El Tiempo, 1953:5).

La infraestructura vial, en relación a su falta y su precariedad en los pueblos del interior, puede ser vista como uno de los factores de expulsión que entra en consideración a la hora de interpretar las migraciones campo-ciudad. Por un lado, la construcción de rutas nacionales y provinciales hacia las cabeceras de partido habría facilitado los movimientos poblacionales, movimientos que a su vez demandaban la renovación y ampliación de la infraestructura vial. Pero, por otro, habría puesto en evidencia las falencias y los contrastes del resto de la red, como fue el caso de los caminos rurales.

En los diagnósticos de intereses y expectativas en torno a los caminos, debe tenerse en cuenta un elemento no considerado por la historiografía: el auge de camionetas y camiones en el campo. Hacia 1960 la declinación del servicio ferroviario sin inversiones durante las últimas décadas dio lugar a que el transporte de cargas por camión, puerta a puerta, asumiera aún más importancia. Según un informe de la CEPAL, el movimiento de carga entre 1938 y 1955 muestra un estancamiento del tráfico ferroviario y un aumento progresivo del tráfico caminero (Cuadro 1). 
Cuadro 1. Tráfico de carga realizado por medio de ferrocarriles y automotores en la Argentina (1938-1955), promedios anuales expresados en millones de tn-km. Fuente: Ministerio de Obras Públicas, DNV (1960:7).

\begin{tabular}{|c|c|c|c|}
\hline Años & $\begin{array}{c}\text { Ferrocarril } \\
\text { (millones de tn-km) }\end{array}$ & $\begin{array}{c}\text { Automotores } \\
\text { (millones de tn-km) }\end{array}$ & $\begin{array}{c}\text { Relación } \\
\text { (millones de tn-km) }\end{array}$ \\
\hline $1938-1940$ & 12,6 & 1,6 & 0,13 \\
\hline $1941-1945$ & 16,4 & 2,2 & 0,13 \\
\hline $1946-1950$ & 16,6 & 6,4 & 0,39 \\
\hline $1951-1955$ & 16,6 & 10 & 0,6 \\
\hline 1955 & 16,5 & 10,7 & 0,65 \\
\hline
\end{tabular}

Las expresiones del ingeniero José Luxardo, miembro del Grupo de Planeamiento de los Transportes del Ministerio de Obras y Servicios Públicos de la Nación, también dan cuenta del incremento de los volúmenes de tránsito caminero, en especial a través de camiones:

Se operó un aumento de casi el $50 \%$ en los volúmenes de tránsito en caminos rurales entre 1955 y 1960, observándose en la composición del mismo un alto porcentaje en camiones que en promedio alcanza el $45 \%$ (...) Con respecto al transporte de pasajeros por caminos aumentó en un 20\% y el de cargas en un 50\% en el período 1955-1950 (Asociación Argentina de Carreteras, 1962, julio-septiembre:11).

Dicha tendencia alcista a nivel nacional se corrobora al medir el parque automotor de la provincia de Buenos Aires entre mediados de los años cincuenta y sesenta (Figura 1).

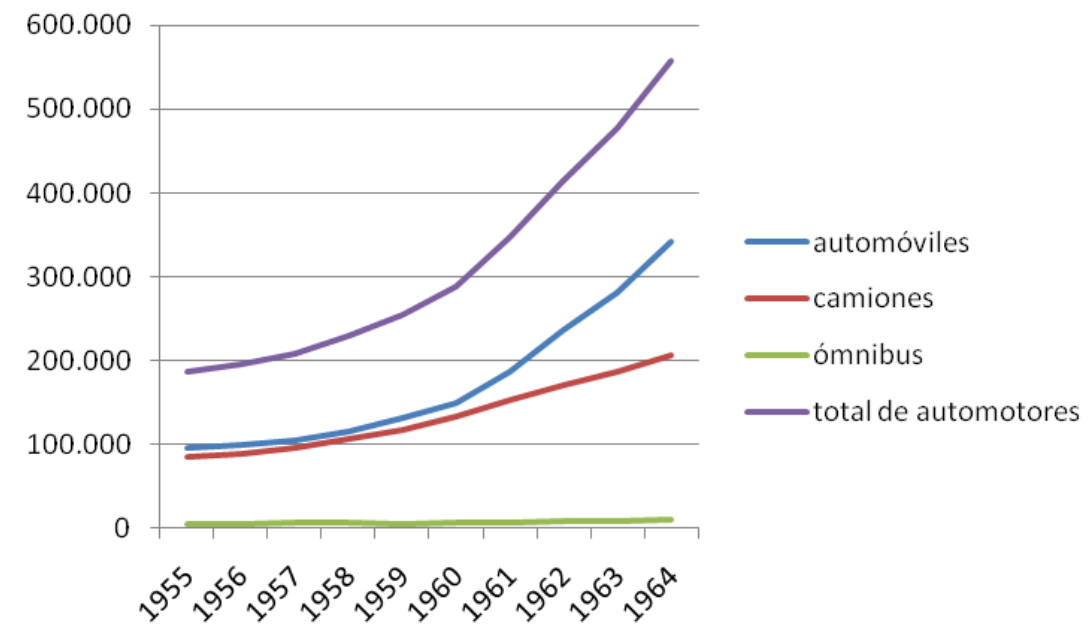

Figura 1. Parque automotor de la provincia de Buenos Aires (en unidades), 1955-1964. Fuente: Asociación de Fábricas de Automotores (1966:25).

Con estos datos a la vista, resulta factible señalar que el déficit del ferrocarril hizo que la red caminera construida hasta entonces sufriera las consecuencias del desequilibrio económico-funcional de los medios de transporte. Como los caminos no habían sido erigidos para soportar la densidad de un tránsito tan pesado, naturalmente sufrieron roturas. Lo puntualizó con claridad Marcos Sastre, representante de la Asociación Argentina de Carreteras en el Primer Congreso Vial de la Provincia de Buenos Aires: "como usuarios de los caminos hemos constatado la destrucción de los mismos (...) una de las razones -no la única, pero una de las más poderosas- es el peso de los camiones que, aumentado por la velocidad, agravan el problema" (Primer Congreso Vial de la Provincia de Buenos Aires, 1960:50). Pero ésta no fue una intervención aislada. De hecho, los límites de carga, velocidad y dimensión de los vehículos, en relación a la destrucción vial ocasionada, a la legislación, a la fiscalización y a los impuestos, se erigió como uno de los temas centrales de dicho congreso. 
Por otro lado, mientras las actividades industrial y agropecuaria crecían y el transporte ferroviario decaía, mermaba la atención gubernamental al sistema vial. El presupuesto vial de entre mediados de las décadas de 1940 y 1950, disminuido en términos reales respecto al de años anteriores, se empleó casi totalmente en gastos de conservación, y resultó aún insuficiente para ello. Esto marcó una disparidad con la década de 1930, signada por un fuerte activismo. Como hemos apuntado, la Ley Nacional de Vialidad 11.658/32 había determinado la construcción de un sistema troncal de caminos que cruzaran todo el territorio, comunicando capitales y centros de producción y permitiendo el acceso a países limítrofes, puertos y estaciones ferroviarias. Para ello se creaba un ente administrativo autárquico, encargado de proyectar, construir y conservar la red, la DNV. Se fijaba la formación de un fondo permanente para facilitar la acción continua y eficaz y se estipulaba un sistema de acogimiento por parte de las provincias con un criterio de coordinación y fomento.

La Dirección de Vialidad de la Provincia de Buenos Aires (DVPBA, así llamada a partir de 1936), fue una de las entidades provinciales más fecundas en cuanto a obras por cuenta propia. Luego de su acogimiento a la normativa nacional, por medio de la Ley 4.117/32, consolidó la vialidad como objeto de políticas públicas. Al respecto, resultó emblemático el Plan Vial de 1937 durante el gobierno de Manuel Fresco, que preveía el trazado de una red de caminos de enlace con la red nacional, favoreciéndose el acceso a puertos, zonas de producción y, especialmente, destinos turísticos (Fernández, 2016). Inspirado por criterios de modernización y racionalidad, puso en evidencia el avance del Estado provincial en materia vial (Piglia, 2011). La búsqueda de intercomunicación y de complementación de la red troncal justificaba la proyección de obras.

A nivel nacional, el impulso inicial se prolongó sólo durante una década. En 1943 la DNV fue intervenida, y lo mismo sucedió en 1947 con la DVPBA. Con la pérdida de su autonomía se deterioró su organización y se paralizaron las realizaciones, fenómenos que a los cuales incidieron también el impacto de la segunda guerra mundial, la inflación, el cambio de prioridades gubernamentales y la ampliación de los gastos en conservación. Pese a que durante la gobernación de Domingo Mercante (1946-1952) la provincia fue testigo de una prolífica construcción de obras de infraestructura (Lacunza, 2004), las obras viales se condensaron en los distritos que estrechaban centros turísticos, productivos y comerciales. La prioridad a caminos de bajo costo dejó al rezago la interconexión de pueblos y parajes.

Por estas razones, el sistema vial de la provincia contenía serias deficiencias: era insuficiente y mayormente de tierra (Figura 2), estaba mal conservado y en su mayoría se hallaba a cargo de municipios que no contaban con recursos necesarios.

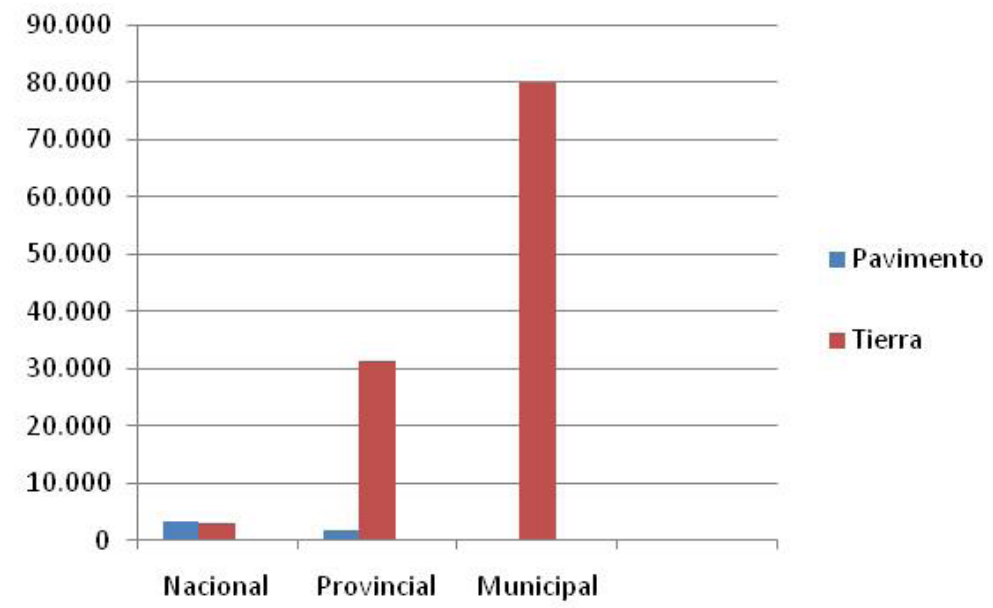

Figura 2. La red vial en la provincia de Buenos Aires (en km), 1959. Fuente: Cámara de Diputados de la Provincia de Buenos Aires (en adelante, CDPBA) (1959:3495). 
Un agravante empeoraba la situación: los suelos bonaerenses, excelentes para la explotación agrícola-ganadera, eran en general malos para ser usados en la construcción vial. Las constantes e intensas lluvias del otoño e invierno solían generar anegamientos, ante la dificultad de drenaje por las escasas pendientes naturales para escurrir las aguas hacia los canales, arroyos y ríos. A esto se le suma la carencia de obras de infraestructura hídrica, tales como canalizaciones y obras de regulación. Como resultado, con frecuencia las lluvias provocaban huellas y pantanos que impedían la circulación de vehículos tanto de carga como livianos, afectando la suerte de productores, transportistas y vecinos en general.

Ante este cuadro no es de extrañar que Noticias Camineras denominara "impuesto al barro" al originado de la utilización de caminos de tierra, el cual se traducía en un acelerado desgaste de las unidades y en un mayor consumo de nafta (Asociación Argentina de Carreteras, 1955, octubre 18:44). Por entonces, en condiciones de buena transitabilidad se estimaba que el costo total por automóvil-kilómetro en caminos de tierra era de $\$ 2,11$. En cambio, en las condiciones de la provincia -con malos trazados, pantanos, obras de drenaje y abovedamiento precarias, etc.--, se calculaba un $25 \%$ más, es decir, $\$ 2,64$. En caminos pavimentados, el costo se valuaba en $\$ 1,36$. Para camiones, se calculaba $\$ 4,08$ en pavimentos, $\$ 6,33$ en caminos de tierra mejorados y $\$ 7,92$ en caminos de tierra (MOPBA, Dirección de Vialidad. Plan Vial 1959-1963. Tomo II:4546.). Estos guarismos dejan al descubierto los perjuicios económicos que aparejaba el mal estado de los caminos existentes; y a esto debe sumársele la incomunicación que sufrían muchos parajes.

En suma, en los años cincuenta y sesenta los cambios sociales y económicos dieron lugar a una sociedad rural más compleja y con nuevas necesidades en materia vial. El acortamiento de distancias, la reducción de costos y la agilización de traslados se convirtieron en demandas no completamente novedosas, pero sí más asiduas por parte de los habitantes de las zonas rurales. En este contexto, fue cobrando fuerza un nuevo tipo de intervención provincial, más planificado y orientado al estudio y la solución de los problemas del interior.

\section{Las ideas en primer plano: un resurgir de inquietudes en materia vial}

Ya desde los años veinte, la red caminera era vista como uno de los motores del progreso y la modernización del país (Ballent, 2005). No sólo se la entendía como un medio de abaratar los costos de la producción agropecuaria. Indisolublemente vinculada a la cultura del automóvil -que incluía el deporte, los modernos hábitos de transporte y las nuevas prácticas turísticas-, se la asimilaba a una causa patriótica, cuya planificación y coordinación le correspondía al Estado. El papel de la acción privada se reducía a la asesoría y al control de las iniciativas, aunque fue clave para la configuración de la vialidad como un problema público, tal como quedó plasmado en la Ley Nacional de Vialidad de 1932. Al respecto, merecen mención las redes asociativas, entre las que se destacan el Automóvil Club Argentino y, en especial, el Touring Club, cuyas contribuciones tuvieron un peso decisivo en la diagramación de diagnósticos y soluciones posibles (Piglia, 2014). En materia de circulación de ideas, constituía un lugar común la proyección de una trama vial que superara al abanico ferroviario y lograra una auténtica integración nacional, acercando las zonas aisladas a las centrales. Sin embargo, las obras efectuadas distaron de aquel anhelo: no lograron construir una red que, con sentido de complementariedad, trascendiera aquel abanico de hierro.

En los años cincuenta se avizora una revalorización de la cuestión vial, de la mano de los bríos internacionales. En 1948 se constituyó la International Road Federation y 
varios países latinoamericanos fundaron asociaciones nacionales afines. Se trataba de un hecho nuevo la conformación de entidades dedicadas a poner de relieve la importancia del camino y a establecer un activo intercambio de conocimientos y experiencias acerca de la técnica vial entre todos los actores de la actividad, más allá de las fronteras nacionales. En la Argentina, fue sintomática la fundación en 1953 de la Asociación Argentina de Carreteras, entidad civil adherida a la International Road Federation que, integrada por funcionarios, académicos, empresas constructoras, fabricantes e importadores de equipos y asociaciones de automovilismo, se proponía interesar y asesorar a los poderes públicos en los planes de ejecución de obras viales. A través de sus órganos de prensa -Noticias Camineras (creada en 1954, mensual) y Revista Carreteras (lanzada en 1955, trimestral)-, sus investigaciones, jornadas técnicas y académicas y publicaciones bregaba por remover los obstáculos técnicos, administrativos, financieros y políticos para la construcción de más y mejores caminos. En particular, a partir de 1955, sus ideas se volvieron parte de un programa explícito de acción pública, en el marco del cambio de gobierno y de nuevas formas de articulación entre sociedad civil y Estado. De modo análogo, la Cámara Argentina de la Construcción organizaba ciclos de conferencias y debates, a fin de estudiar y discutir un "problema de gran magnitud: el de la necesidad e importancia para el país de intensificar la construcción de carreteras" (Cámara Argentina de la Construcción, 1952). En la Revista de Desarrollo Económico, publicación de la Junta de Planificación Económica de la Provincia de Buenos Aires, también se plasmaron los debates teóricos sobre el desarrollo económico y sus vínculos con el transporte. En su primer número, en 1958, advertía que "la importancia del problema vial aconseja se analice con más detalle las inversiones en esta materia" (Junta de Planificación Económica de la Provincia de Buenos Aires, 1958:242).

Los concursos fotográficos, los certámenes escolares, las muestras audiovisuales y las conferencias alusivas ponen en evidencia cómo el camino mantenía una gran fuerza inspiradora. El renovado impulso que habría cobrado la cuestión es ilustrado también por el lanzamiento de nuevos congresos viales, tales como el Primer Congreso Vial de la Provincia de Buenos Aires en 1959 y el Primer Congreso Municipal Vial de la Provincia de Buenos Aires en 1961. Los diarios tampoco escapaban de esta tendencia. Anualmente, en oportunidad de la celebración del Día del Camino, instaurado en 1933, El Día ofrecía una detallada reseña de la labor caminera cumplida en la provincia, así como notas de opinión por parte de expertos o autoridades viales. En todas las expresiones se vislumbra una profunda conciencia vial que atribuía a los caminos un valor fundamental para el desarrollo económico y social, al tiempo que se insistía en su desgaste y destrucción, producidos por la intensificación del tránsito en las postrimerías de la segunda guerra mundial. Expresaba el periódico mencionado: "El automotor ensancha el cuadro antes estrecho de sus perspectivas y llegan el camión y el ómnibus a competir (...) con el ferrocarril (...) En virtud de esta evolución, el camino ha pasado a ser en nuestros tiempos una prioridad del progreso y un fundamento de la economía" (El Día, 1961:13). Desde una óptica similar, el periodista Gordon Symes puntualizaba en la Revista Carreteras: "Las comunicaciones viales no constituyen sólo un aspecto del desarrollo -en competencia con los proyectos sanitarios, educacionales o industriales-, sino que son un requisito previo esencial para todos ellos" (Asociación Argentina de Carreteras, 1961:30).

A mediados de la década de 1950, el discurso relativo al rol de la red vial en la actividad y comercialización agropecuaria fue como un universo en expansión. El afán por el transporte caminero de la producción agropecuaria, aunque no era novedoso, resurgió con fuerza. Este paradigma que enlazaba transportes y desarrollo abrevaba en las ideas desarrollistas que promovían el rol decisivo del Estado para modernizar el aparto productivo (Altamirano, 1998; Sikkink, 2009; Lázzaro, 2012). Resulta ilustrativo que lo que habría popularizarse como el Plan Prebisch, presentado en 1955, señalara que uno de los grandes obstáculos que desalentaban la modernización de la empresa rural 
eran las carencias en materia de energía y transportes (viales y ferroviarios) (Prebisch, 1955). Este diagnóstico, que dio pie a la recomendación de una intervención estatal planificada en coordinación con la iniciativa privada, formaba parte del clima de ideas de la época. Conforme a este espíritu, el estancamiento económico y la disminución de la calidad de vida en el interior eran atribuidos, entre otros elementos, a la falta de medios de comunicación. Por ejemplo, la Asociación de Cooperativas Argentinas, a través de su órgano oficial de expresión, reclamaba por la "carencia de caminos, la falta de electricidad, de escuelas, de asistencia médica y de mínimo confort" (Asociación de Cooperativas Argentinas, 1958:3). Un planteo similar formuló la Cámara Argentina de la Construcción.

La contención del éxodo del hombre de campo hacia los centros poblados, el incremento de las explotaciones (...), abaratamiento del producto en los centros de consumo, divisas extranjeras que nos son tan necesarias, la radicación de industrias en el interior del país y hasta la misma solución del problema tan afligente de la vivienda dependen esencialmente de nuestra red vial (Cámara Argentina de la Construcción, 1959:6).

En el Segundo Congreso Vial de la Provincia de Buenos Aires, celebrado en 1960, Filiberto Bibiloni ilustró varias cuestiones significativas sobre la relevancia socio-cultural de los caminos:

El problema(vial) no es solo tecnológico yeconómico; es también y fundamentalmente un problema social (...) Entendemos y creemos conveniente volver al interior, pero solamente podremos volver el día que tengamos en el interior trabajo promovido, especialmente, por energía y caminos (...) Pero, además de los problemas sociales, también toca a los aspectos culturales. Con caminos, con energía y con trabajo en el interior podremos resolver los problemas sociales del Gran Buenos Aires (...) Solamente con caminos podremos llevar al interior educación y cultura (...) Cuando se puedan desplazar con facilidad y con comodidad, los habitantes irán gustosos al interior, caso contrario, el problema no tiene solución (Ministerio de Obras Públicas de la Provincia de Buenos Aires (en adelante, MOPBA), Dirección de Vialidad, 1960:52).

Si bien las reflexiones sobre la necesidad de arraigo a la tierra datan de los años treinta, fue a partir de los sesenta cuando se tiñeron de dramatismo. La situación era juzgada apremiante y obligaba a adoptar medidas sin demora, puesto que se pensaba imposible frenar el éxodo rural y la concentración urbana sin antes un mínimo nivel de bienestar material y espiritual en el campo. Reclamaba un editorial de Noticias Camineras en 1955: "el campesino no debe sentirse realizador de un bienestar que él no llega a tener a su alcance (...) Dentro de las diversas medidas para hacer esto posible, deben fomentarse especialmente las buenas comunicaciones" (Asociación Argentina de Carreteras, 1955, junio 14:1). En la misma dirección afirmaba el ingeniero Marcelo Álvarez:

El abandono de la red vial vecinal contribuye a mantener el aislamiento espiritual y material de los habitantes del campo y los pequeños núcleos poblados, agudizando el contraste con las mayores posibilidades de los grandes centros urbanos. Mientras un país no resuelva en forma integral el problema de sus comunicaciones interiores, sus habitantes no lograrán el mínimo standard de vida (...) (Asociación Argentina de Carreteras, 1957:14-15).

Cabe destacar que la ligazón entre transportes, comunicaciones, bienestar rural y desarrollo remitía a un espíritu amplio antes que a una ideología, y que la misma poseyó diversos focos de incitación (políticos, intelectuales y técnicos), algunos de ellos de carácter internacional. Entre estos focos hay que recalcar el de la FAO y la CEPAL, 
aunque su influencia no fuera equiparable a la de otros países latinoamericanos (FAO, 1954; CEPAL, 1959). Por ejemplo, esta última organización expresaba: "los automotores constituyen en muchos aspectos un importante factor de descentralización y de mayor difusión de las actividades económicas" (CEPAL, 1959:59).

En el mismo sentido, e inscripta en una visión de largo plazo, la infraestructura vial era concebida como una vía de descentralización social, política y económica por distintas personalidades de los arcos político y empresarial. Luis de Carli, presidente de la Asociación Argentina de Carreteras alegaba: "los caminos deben compensar las faltas de los ferrocarriles (...) Es necesario para que la vida rural sea tolerable, que el hombre de campo tenga fácil acceso a los centros civilizados. Sólo así descongestionaremos los grandes centros urbanos", en una nota para El Día (El Día, 1959:10). En la misma línea, la Cámara Argentina de la Construcción exhortaba al gobierno a promover el desarrollo del interior de la provincia, a través de, entre otras medidas, la descentralización de las vías de comunicación (Cámara Argentina de la Construcción, 1959:71). A lo mismo apuntaba el presidente de la DVPBA, el ingeniero Rafael Balcells, en una entrevista para El Día: "intercomunicar (...) De esta manera, evitáranse los rodeos y descentralizaremos nuestra estructura comercial” (El Día, 1961:13).

Así, se advierte en los años cincuenta una trama de instituciones estatales y asociaciones sólidamente asociada a la perspectiva de descentralización, tanto en el plano material como el simbólico. Dicha visión trasciende a la mera intercomunicación, puesto que implica la dispersión o distribución de funciones y poderes fuera de una autoridad o ubicación nodal. De este modo, puede afirmarse que el esquema conceptual cepaliano centro/periferia para describir la configuración desigual de la economía mundial tuvo su correlato en la interpretación local. Esto queda demostrado por la difusión -aunque a paso lento y con alcance disímil- de ideas referidas al abanico caminero como símbolo de la estructura colonial. Horacio Zubiri, ministro de Obras Públicas de la Provincia de Buenos Aires entre 1958 y 1961, afirmaba: "Ese abanico rojo que se muestra en todos los mapas de vialidad es el símbolo de un país que vive con rango de colonia. Queremos romper con ese centralismo (...) y por eso vamos a promover el desarrollo del interior" (Alende, 1958:82).

Concomitantemente, había quienes insistían en la incidencia económica y social de la red caminera en las áreas marginales. Al respecto, es ilustrativo el discurso de Rafael Balcells, en el Primer Congreso Vial Municipal, celebrado en 1961: "Por esos caminos (municipales) transitan los pobladores de las regiones más apartadas de nuestra provincia que son los que disponen, por ese motivo, de menos acceso a los centros educacionales, de cultura y de esparcimiento y por eso merecen ser considerados con un gran criterio de prioridad" (...)" (Asociación Argentina de Carreteras, 1962, eneromarzo:16). La Federación Económica de la Provincia de Buenos Aires, en el Primer Congreso Vial de la Provincia de Buenos Aires, instaba a que los estudios viales guardaran una relación directa con la redistribución de las fuentes de riqueza, la industria, el comercio y la producción (Primer Congreso Vial de la Provincia de Buenos Aires, 1960:322). Por su parte, Horacio Ball, presidente de la Confederación de Asociaciones Rurales de Buenos Aires y La Pampa (CARBAP), señalaba: "hacen falta caminos transversales (...) El inteligente trazado de una red caminera no sólo contribuirá al desarrollo comercial, sino que simultáneamente propenderá a radicar nuestra población campesina" (Asociación Argentina de Carreteras, 1958:42). En consonancia con estas ideas, aunque lógicamente más interesado por el automovilismo y el turismo, el Automóvil Club Argentino también destacaba que, entre muchos otros beneficios, el camino "lleva el campo a la ciudad y la ciudad al campo" (Automóvil Club Argentino, 1953:3).

Otra idea que fue objeto de referencia común para análisis y prescripciones dentro del pensamiento social y económico fue el desarrollo de la comunidad, local o municipal. 
Resulta emblemática una publicación del Instituto de Planeamiento Regional y Urbano de Buenos Aires (fundado en 1952), la cual aseveraba: "La autoridad municipal es responsable del desarrollo (...) La mejor forma de preparar condiciones locales de receptividad frente a la descentralización metropolitana consiste en que cada municipio formule un programa de desarrollo" (Instituto de Planeamiento Regional y Urbano, 1962). De allí el aliento a los gobiernos municipales para que, con recursos humanos y financieros propios y supralocales, formularan y pusieran en marcha iniciativas de desarrollo urbano y rural que incluyeran a la red vial. Por entonces, esta última fue más identificada como un asunto que afectaba a los habitantes de las localidades del interior y que merecía la atención integral (técnica, jurídica y económica) de todos los poderes públicos (nacionales, provinciales y municipales) y del compromiso vecinal; no sólo le cabía la responsabilidad a la DNV. Como la misión no era sencilla ni se lograría de un día para otro, exigía una acción conjunta. En los noveles Congresos de Vialidad organizados por la provincia de Buenos Aires -el Primer Congreso Vial (1959), el Segundo Congreso Vial (1960), el Primer Congreso Vial Municipal (1961)- se alcanzaron consensos en torno al rol del Municipio y de los vecinos en materia de vialidad, contribuyendo a la concepción de ésta como un problema también local. En especial, las experiencias de EEUU, México, Perú y Venezuela eran tomadas como modelo, por sus exitosos sistemas tripartitos de financiamiento (nacional, regional y particular).

La prioridad de una planificación centralizada y sistemática de la red vial vecinal también era demandada por las asociaciones y autoridades viales (Asociación Argentina de Carreteras, 1955, enero-marzo:22). Resultan ilustrativas las palabras del ingeniero y docente universitario Ludovico Ivanissevich Machado en una nota publicada en Autoclub: "La legislación y las realizaciones deben orientarse en el sentido de canalizar y favorecer el pujante impulso vecinal” (Automóvil Club Argentino, 1966:125.). Similar arenga se observa en los periódicos locales, como en la nota que la Federación Agraria Argentina publicara en El Independiente de General Alvear: "solicitamos se hagan reuniones zonales de vecinos en cada cuartel para que se organice un plan práctico en colaboración y se acepte su participación en los trabajos y sus conocimientos para (...) reconstruir los caminos (...)”. (El Independiente, 1958:1). El análisis de las fuentes permite ver cómo, desde el plano discursivo, la descentralización refuerza el principio de participación colaborativa.

Resumiendo, las fuentes demuestran que muchas de las imágenes referidas a la vialidad abrevaban en una historia más larga. No eran nuevos, en efecto, ni la preocupación por dar impulso al agro y a la industria ni la voluntad de fomentar la integridad nacional, que se habían hecho manifiestas desde los años veinte. Tampoco lo era la comparación con otros países o la vialidad como contribución al perfeccionamiento del federalismo. Lo que sí era inédito era el vocabulario, por parte de los representantes de ámbitos políticos, técnicos y productivos, sobre la descentralización y el énfasis en el rescate de las iniciativas locales como camino al desarrollo, en consonancia con el auge del desarrollismo. A continuación, caracterizaremos el modo en que el Estado provincial canalizó esos renovados intereses a través de la implementación del Plan Vial 1959-1963.

\section{El gobierno toma la iniciativa}

La presidencia de Arturo Frondizi, iniciada en 1958, implicó la consolidación de una orientación desarrollista impulsora del ingreso de capital extranjero, la producción de bienes intermedios y de capital y la mecanización del agro. Esta orientación conllevaba la voluntad de subordinar las políticas redistributivas y priorizar, en cambio, la rentabilidad empresarial y la inversión estatal en obras de infraestructura, en un momento 
en que éstas eran percibidas como apremiantes. Se argumentaba que balanza comercial negativa, estancamiento de la producción agropecuaria, deficiencias en el sistema energético y ferroviario, industrias desintegradas e inflación imponían serios obstáculos al tan mentado desarrollo. Ante esta realidad, ninguna actividad podía funcionar, todas estaban condenadas al atraso. De allí que, en función de la mejora de la productividad debían estimularse, entre otras políticas, caminos eficientes y transportes fluidos (Frondizi, 1965). La realidad indica que, a pesar de su firme convicción en el diagnóstico, la política pública no fue lineal, al transitar de una etapa propiamente desarrollista hacia otra en la que, ante la explosión inflacionaria y las presiones corporativas, se buscó primordialmente la estabilización económica y financiera. Además, dentro del rubro infraestructura, el gobierno priorizó ante todo el fomento de la actividad petrolera nacional.

Las Memorias de la DNV exhiben que en el período 1959-1961, sólo fueron inaugurados $5.001 \mathrm{~km}$ de nuevos caminos, pese al ambicioso proyecto a ejecutar en el decenio 1959-1969 (DNV. Memoria 1959-1961). De todos modos, merece mención la sanción de dos leyes que allanaron la concreción del Plan Vial bonaerense. Las mismas se sumaron a aquella que desde 1956 restituía la autarquía de la DNV y a la que desde 1958 estipulaba una nueva escala de gravámenes a los combustibles en beneficio de los ingresos provinciales (aunque, en este último caso, hubo problemas para su recaudación). Primero, la Ley 15.274/60 amplió el fondo nacional de vialidad con recursos provenientes de los impuestos al consumo de cubiertas y a los vehículos automotores pesados. El 35\% de lo obtenido por estos gravámenes se prorratearía entre las provincias y la Capital Federal. Segundo, la Ley 15.275/60 tenía por finalidad principal facilitar, adelantar y acelerar la construcción de obras viales en la red nacional, mediante la contratación y licitación por parte de la DNV.

En la provincia de Buenos Aires, el gobernador Oscar Alende desplegó una agenda pública que no siempre coincidió con la del nivel nacional. A su gobierno se lo suele asociar con la reforma agraria e impositiva que, aunque adoptó una versión morigerada de la propuesta, se granjeó la oposición de los grandes productores agropecuarios (Lázzaro, 2008). Junto a ella, singular importancia adquirieron otras políticas públicas menos visibilizadas pero igual demandadas por amplios sectores de la provincia, como fueron las obras viales y energéticas (Panella, 2014:98). Prueba de ello fue que, dentro del Presupuesto del Ministerio de Obras y Servicios Públicos, las Direcciones de Vialidad y Energía abarcaban una singular porción del presupuesto. Por ejemplo, en 1961 los montos representaban, respectivamente, el 59,8\% y el 18,6\% del total, superando ampliamente las partidas destinadas a Arquitectura, Geodesia, Hidráulica, Lemit, Obras Sanitarias, Ministerio y Pavimentación (MOPBA, 1963). La prensa se hizo eco de tal primacía, tal como lo destacó Asuntos Agrarios en una nota titulada "Obras públicas por 442 millones con beneficio directo para la promoción agraria", cuyo copete subrayaba "Caminos y energía siguen constituyendo los rubros preferentes de Bs. As" (Ministerio de Asuntos Agrarios de la Provincia de Buenos Aires, 1961:5). En la planificación gubernativa, Alende fue, sin dudas, un activador fundamental en la propagación de las ideas relativas a la necesidad de expansión y descentralización de la red vial. En su discurso inaugural de sesiones legislativas de 1958 señaló:

(...) la desoladora realidad del estado de los caminos bonaerenses, alejados de la capital que ocasionan pérdidas cuantiosas, inconvenientes y penurias inenarrables para el transportista, para el productor y para el viajero. Por tales razones y hechos, las inversiones en caminos figuran como capítulo primario en nuestras ejecuciones (Cámara de Senadores de la Provincia de Buenos Aires, 1958:33).

Radicar población, frenar el éxodo a las ciudades, impulsar el crecimiento y mejorar las condiciones de vida en la campaña eran los argumentos subyacentes a las propuestas viales. Lo ratificó Alende en la clausura del Segundo Congreso Vial de la Provincia de Buenos Aires: 


\begin{abstract}
la Argentina y la provincia reclaman como una condición fundamental para su desarrollo, las comunicaciones, los caminos y los transportes, para movilizar la producción, para intercomunicar a los pueblos, para crear fuentes de trabajo y para burlar esta estructura que ha hecho concentrar la población en torno de la Capital Federal y mantiene a nuestros pueblos del interior en el abandono, porque al no existir fuentes de trabajo, sus adolescentes abandonan su lugar natal y se dirigen hacia la gran concentración demográfica del conurbano (...) Los pueblos del interior de la provincia, los pequeños pueblos por donde pasarán los caminos de nuestro Plan Vial (...) han disminuido en población desde 1947. Y este hecho dramático que tipifica a una estructura económica de la Argentina y crea tremendos problemas de sociales de perturbación que pueden afectar incluso o tratar de disolver nuestra familia (MOPBA, Dirección de Vialidad, 1960:47).
\end{abstract}

En sus giras por la provincia, el gobernador solía recibir numerosos pedidos de atención a la cuestión caminera. Algunos ejemplos ilustran claramente estas inquietudes. La Sociedad Rural de General Alvear formuló: "Múltiples y complejos problemas son los que tiene esta zona (...) Pero uno de los capitales que atañe a la comunidad y a los componentes de esta Sociedad Rural, es sin lugar a dudas, el problema vial" (El Independiente, 1958:1). Un concejal de Veinticinco de Mayo, José Costa, expresaba la necesidad de dos políticas fundamentales en su distrito: de tierras y vial. En relación a esta última, aducía: "Los caminos no deben ser cuestión de agrupar los centros poblados con (...) la Capital Federal (...) El camino debe estar al servicio de la población agropecuaria" (Alende, 1958:116). Similares planteos respecto a la falta y mala distribución de caminos son perceptibles en otras localidades. La difusión de los reclamos contribuyó a la incorporación de imágenes sociales asociadas a la infraestructura, cuyo poder simbólico en la formación de la problemática del desarrollo -aunque difícil de evaluar- resulta innegable.

A poco de haber asumido Alende, el Poder Ejecutivo propuso y puso en marcha el Plan Vial de la Provincia de Buenos Aires 1959-1963. Éste fue el primero en aprobarse por ley especial (Ley 6.010/58), puesto que los anteriores no sólo incluían obras de menor magnitud, sino que además integraban Planes de Trabajo que abarcaban diversos tipos de rubros (por ejemplo, las Leyes 4.539/37 y 5.142/47). En sintonía con el pensamiento desarrollista, la comisión legislativa encargada de su tratamiento señalaba una crítica situación vial que obligaba a adoptar medidas sin demora: "Complementario del Plan Eléctrico (...) ha sido elaborado en función de un planteamiento integral, basado en las necesidades más apremiantes, de imprescindible realización, si queremos sacar a la provincia del estado de postración económica en que se encuentra" (CDPBA, 1958:3495). Dicho diagnóstico se convirtió en leitmotiv del discurso oficial: las vinculaciones directas y rápidas, sin rodeos, como elemento esencial para superar el subdesarrollo.

Tal visión era asumida por los defensores del Plan, como expresó en el debate legislativo el diputado de la UCRP, Néstor Picado: "las rutas afirmadas conforman un trazado convergente todas ellas en el puerto de Buenos Aires, sin caminos transversales, dejando amplias zonas aisladas totalmente" (CDPBA, 1958:3499). En el mismo sentido, Horacio Zubiri, tildó como "deformada" a la provincia, por la brecha existente entre el área metropolitana y el interior (MOPBA, Dirección de Vialidad, 1959:4). Esta falencia, y el desequilibrio que conllevaba, hundían sus raíces en los años treinta (incluso antes, en la época colonial) por lo que la responsabilidad era atribuida a gobiernos que, o bien habían servido a la oligarquía o bien no habían expresado preocupación por el tema. Imbuidos por las corrientes de pensamiento de la época, los legisladores que intervinieron en la discusión coincidían en que el aislamiento y el estancamiento vial de la provincia constituían serios obstáculos para el crecimiento económico, por lo tanto, reclamaban un 
planeamiento vial integral, moderno y adaptado a los nuevos tiempos. Aseveraba José Quinteros Luques, representante de la Unión Cívica Radical del Pueblo: "En lo que respecta a vialidad estamos a cincuenta años de atraso" (CDPBA, 1958:3515).

Así como el Plan prácticamente no despertó objeciones en el recinto del Congreso (sólo cuestiones de forma), su anuncio tuvo eco favorable por parte de la prensa, tal como lo evidencia El Día: "será de extraordinario beneficio para el desarrollo y el bienestar de la provincia (...) incidirá definitivamente en la radicación en el interior de nuevas industrias, que resolverán paulatinamente el problema del éxodo del hombre de campo" (El Día, 1961:18). La resonancia periodística se explica en gran parte por una razón, esto es, el plan reflejó la cristalización de un consenso en torno a la cuestión caminera que incluyó la demanda de una red transversal que uniera localidades del interior de la provincia.

Por entonces, la longitud de la red provincial era de $33.158 \mathrm{~km}$; de ese total sólo $1.920 \mathrm{~km}$ estaban pavimentados (5,7\%) El programa, al colocar el foco en el trazado transversal desde el norte y el oeste de la provincia hacia los puertos del litoral atlántico, bregaba por el desarrollo del interior. Concretamente, comprendía nuevos pavimentos $(3.000 \mathrm{~km})$, reconstrucción $(300 \mathrm{~km})$, ensanche $(450 \mathrm{~km})$, accesos a poblaciones desde caminos ya pavimentados $(150 \mathrm{~km})$, caminos por el sistema de consorcios $(150 \mathrm{~km})$, obras básicas $(165 \mathrm{~km})$, apertura y rectificación de trazas $(3.547 \mathrm{~km})$, mejora de pavimentos existentes $(1200 \mathrm{~km})$, construcción y reconstrucción de caminos de tierra $(30.000 \mathrm{~km})$; mantenimiento y adquisición de nuevos equipos e impulso al Plan de Caminos de Fomento Agrícola (Dirección de Vialidad de la Provincia de Buenos Aires, 1959, enero-marzo:65) (Figura 3). Tal como fue anunciado, perseguía cuatro propósitos. Primero, alentar la creación de nuevos centros de producción y consumo alejados del Gran Buenos Aires, en virtud del abaratamiento y la agilización del traslado de productos hacia los mercados interno y externo (en este último caso a través de los puertos de Bahía Blanca, Necochea y Mar del Plata). Segundo, procuraba romper con la vieja estructura convergente hacia la capital del país. Tercero, apuntaba a transformar la situación de incomunicación relativa de muchas ciudades y pueblos. Por último, ambicionaba producir la reversión del Gran Buenos Aires hacia el interior bonaerense (MOPBA, Dirección de Vialidad, 1963:1).

La vocación por la racionalidad y la planificación que traslucía el Plan queda en evidencia al observarse la cantidad de estadísticas y gráficos sobre los cuales se hizo la proyección de obras, atendiendo a exhaustivos estudios fundados en índices económicos y viales (superficie, densidad, tránsito, producción agropecuaria e industrial, cantidad y clase de caminos) y en previsiones futuras. La provincia fue dividida en doce zonas y para la elección de las obras se tuvo en cuenta la vinculación con el proyectado trazado de líneas de energía hidroeléctrica del Chocón y Huelches, lo cual evidencia la complementariedad de proyectos.

Las poblaciones del interior relativamente aisladas eran las principales destinatarias del Plan. La distribución geográfica de las obras, en su mayoría fuera del área metropolitana, habría sido propia de un proyecto destinado a concentrar los esfuerzos gubernamentales dentro de ámbitos con potencialidad económica pero marginados hasta entonces. En efecto, los caminos atravesarían espacios de mayor producción, excepcionalmente cruzarían otros de reducidos índices económicos. Un 18\% del total de las inversiones se efectuarían en un radio de $100 \mathrm{~km}$ alrededor de la Capital Federal, quedando el $82 \%$ restante para el resto de la provincia. Con el nuevo trazado, se alternarían los históricos desequilibrios regionales que signaron la configuración histórica de la nación argentina. 


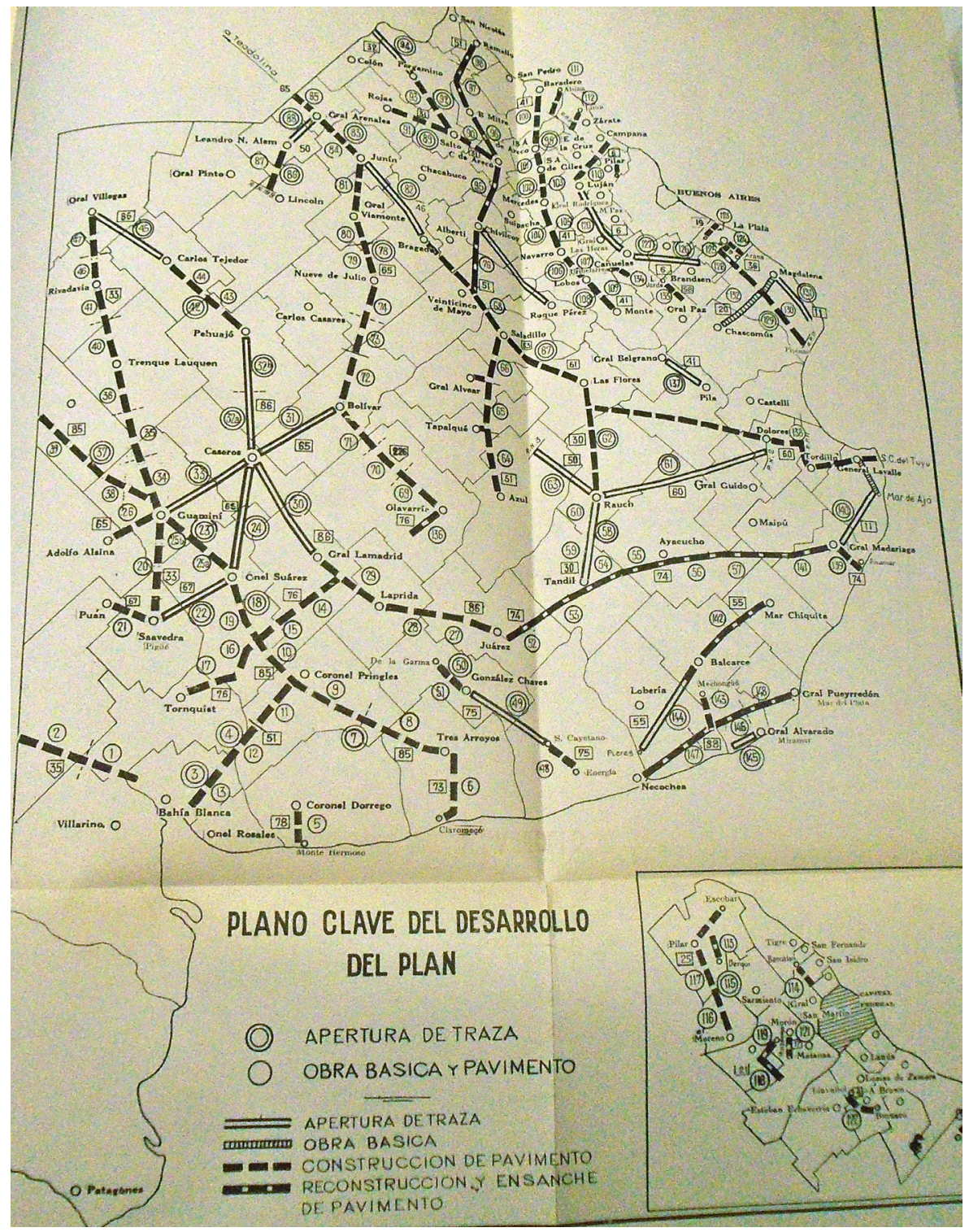

Figura 3. Plano de obras del Plan Vial de la provincia de Buenos Aires, 1959-1963. Fuente: MOPBA, Dirección de Vialidad. Plan Vial 1959-1963. Tomo I.

Cabe agregar una circunstancia que ampliaría la capacidad de trabajo: la creación en 1959 de la Escuela de Ingeniería de Caminos para posgraduados, por parte de la DPBA. La misma, mediante una preparación teórico-práctica intensiva, suministraría ingenieros capacitados para estudiar, proyectar y fiscalizar las obras del Plan Vial. Ubicada en la sede central de la Dirección, desarrollaría un curso intensivo de un año con clases diarias de lunes a sábado a tiempo completo, abarcando treinta y dos materias en el plan de estudios. Los estudiantes, luego de atravesar un proceso de selección, aparte de cursar las asignaturas recibirían un sueldo mensual y asumirían el compromiso de prestar sus servicios en la repartición durante un año a partir de la terminación del curso (Dirección de Vialidad de la Provincia de Buenos Aires, 1959, enero-marzo:67 y agosto-septiembre:3-4). Queda en evidencia entones el interés gubernamental por la formación profesional para el desarrollo de la política vial.

Otro aspecto para destacar es la confianza gubernamental en el desempeño de las empresas contratistas, tanto nacionales como extranjeras. Para fomentar la iniciativa privada, el Plan era respaldado con un ordenamiento legal que aseguraba condiciones de celeridad, 
seguridad jurídica y un adelanto del $30 \%$ a la realización de obras. El programa de trabajos preveía una inversión total de \$5.995.620.000 -luego elevada a \$ 6.699.600.000proveniente de cuatro fuentes: coparticipación federal (20\%), impuesto a los combustibles (25\%), recursos provinciales (53\%) y "varios" (2\%). La magnitud de los recursos destinados a vialidad se inscribió dentro de una creciente presencia del Estado en la construcción de infraestructura. Al examinar los datos disponibles a nivel desagregado, se observa que las partidas destinadas al rubro vial se situaron muy por encima de los valores verificados previamente. Aunque hacia 1962, el incremento del costo de la obra vial -resultante de la modificación del régimen cambiario y de la reestructuración económica- junto a imprevisiones y dificultades económicas disminuyeron el ritmo constructivo e impactaron en las empresas contratistas. Como corolario, la inversión prevista en 1958 aumentó considerablemente, llevando los costos a los 25.000 millones de pesos (MOPBA, Dirección de Vialidad, 1963:3). A pesar de ello, deben rescatarse la magnitud y los rasgos innovadores de las obras que, a nuestro juicio, confirman el activismo y la planificación orgánica que, en materia vial, manifestó el gobierno de Alende.

\section{Reflexiones finales}

El trabajo evidencia cómo, a mediados del siglo XX, las demandas generadas por la expansión agropecuaria (auge de exportaciones, mayores uso y carga de camiones, difusión de tecnología, incentivos gubernamentales al agro), el derrumbe ferroviario y las transformaciones sociales (éxodo rural, incremento de viajes a la ciudad, nuevas pautas de consumo, mayor valoración del modo de vida urbano) motivaron intereses y expectativas en torno a los caminos del interior de la provincia de Buenos Aires. $\mathrm{Su}$ falta, estado precario y diagramación esencialmente radial se convirtieron en un asunto de interés público, luego de una década de relativo estancamiento de inversiones y de obras en relación a años anteriores. Prensa local, autoridades municipales y representantes de diversas entidades civiles (Asociación Argentina de Carreteras, Cámara Argentina de la Construcción, CARBAP, Automóvil Club Argentino, etc.) se hicieron eco de tales inquietudes. Si bien la reducción de distancias y costos, así como la agilización de traslados, no eran quejas completamente originales, sí se tornaron más agudas. De este modo, con su revitalización, la cuestión vial pasó a ser un problema socialmente problematizado.

En este contexto, fue cobrando fuerza un nuevo tipo de intervención provincial, más planificado y sistemático, encauzado al estudio y la solución de las dificultades del interior rural. El Plan Vial 1959-1963, desplegado bajo la gobernación de Oscar Alende, fue una condensación de dicho modo de intervención estatal, que se destacó por su alcance y magnitud en pleno auge del desarrollismo. Esencialmente, preveía la construcción de un sistema de rutas trasversales que cortaran el haz convergente hacia la Capital Federal, vinculando áreas del interior bonaerense entre sí y con los puertos de Bahía Blanca, Necochea y Mar del Plata. La consecución de este proceso abrevó en un discurso oficial que pregonaba la responsabilidad del Estado en la reducción de la macrocefalia de la Capital y el Gran Buenos Aires, mediante el desvío de la promoción económica hacia otros lugares de la provincia.

A través del análisis de la forma en que la obra de la DPVBA fue presentada, se ha tratado de mostrar que la acción sobre el territorio provincial no era concebida en términos exclusivamente productivos, sino que también -aunque en menor medida- en términos sociales y simbólicos. Si bien las advertencias sobre la necesidad de arraigo a la tierra, impulso a la actividad agropecuaria y de integración nacional se remontan a la década del treinta (o incluso antes), fue a partir de mediados de los años cincuenta cuando asumieron un cariz más dramático. Al respecto, los expertos juzgaban que era 
tan imposible acrecentar el comercio exterior sin la mejora del transporte de cargas, como aplacar el éxodo rural y la acelerada urbanización (con los conflictos que ello acarreaba) sin antes un mínimo nivel de bienestar material y espiritual en el campo. Y en esto la infraestructura vial jugaba un papel destacado. Así, el imperioso arraigo al campo, el acortamiento de distancias y la inversión centro-periferia constituyeron temas forjadores de imágenes alrededor del camino. Dichas imágenes, influidas por el esquema conceptual cepaliano, trascendían el afán por la mera intercomunicación de pueblos y parajes, puesto que reconocían la existencia de desequilibrios regionales y deficiencias estructurales, sólo factible de ser revertidas mediante la transferencia de infraestructura y recursos a ámbitos externos al área metropolitana.

De este modo, vistas en el largo plazo, las representaciones muestran continuidades que respondían a una amalgama de procesos estatales, sociales, económicos y políticos complejos. Pero identificar estos vínculos no implica negar el carácter novedoso del Plan. Erigido con una lógica de descentralización, cuidada planificación, equilibrio territorial, amalgama público-privada y valoración de lo local, fue una respuesta a un conjunto de necesidades y transformaciones sociales propias de su época. Su génesis estuvo marcada por su organicidad, su ambiciosa propuesta y el saber experto, y contó con amplios consensos. Ahora bien, queda pendiente para futuras investigaciones indagar hasta qué punto se puso en práctica un programa de tal envergadura, que apuntaba a reemplazar el esquema radial por otro transversal, así como el impacto de las obras efectivamente realizadas. 


\section{Q Bibliografía}

» Albaladejo, C. (2017). Dinámica de la inserción territorial de la agricultura pampeana y emergencia del agribusiness. En C. Gras y V. Hernández (Comps.), El agro como negocio: Producción, Sociedad y Territorios en la Globalización. Buenos Aires: Biblos. Recuperado de https://hal.archives-ouvertes.fr/ hal-01585737/document (5/11/2018).

"Alende, O. (1958). Síntesis de problemas y soluciones expuestos durante las giras del señor gobernador. La Plata: Dirección de Prensa.

»Altamirano, C. (1998). Desarrollo y desarrollistas. Prismas 2, 75-94.

»Asociación Argentina de Carreteras (1955, enero-marzo). Carreteras 1.

»Asociación Argentina de Carreteras (1957, octubre-diciembre). Carreteras 12.

"Asociación Argentina de Carreteras (1958, julio-septiembre). Carreteras 15.

»Asociación Argentina de Carreteras (1961, julio-septiembre). Carreteras 25.

》 Asociación Argentina de Carreteras (1962, enero-marzo). Carreteras 27.

» Asociación Argentina de Carreteras (1962, julio-septiembre). Carreteras 29.

》Asociación de Cooperativas Argentinas (1958, diciembre 26). La Cooperación.

»Asociación de Fábricas de Automotores (1966). Anuario 1966. Recuperado de http://www.adefa.org.ar/es/estadisticas-anuarios (10/12/2018).

»Automóvil Club Argentino (1953, julio). Automovilismo Nº 370.

» Automóvil Club Argentino (1966, octubre). Autoclub, Revista de Automovilismo, Turismo e Informaciones № 11.

»Ballent, A. (2005). Kilómetro Cero: la construcción del universo simbólico del camino en la Argentina de los años treinta. Boletín del Instituto de Historia Argentina y Americana Dr. Emilio Ravignani 27, 107-136.

»Ballent, A. (2008). Ingeniería y Estado: la red nacional de caminos y las obras públicas en la Argentina, 1930-1943. História, Ciências, Saúde - Manguinhos 15(3), 827-847.

"Balsa, J. (2006). El desvanecimiento del mundo chacarero. Transformaciones sociales en la agricultura bonaerense, 1937-1988. Bernal: UNQ.

»Barsky, O. y Gelman, J. (2001). Historia del agro argentino. Desde la conquista hasta comienzos del siglo XXI. Buenos Aires: Grijalbo.

»Brie, R. (1977). Estructura social de los sectores medios rurales. Un análisis de la Región Pampeana. Tomo 1: La familia rural. Buenos Aires: INTA.

»Cámara Argentina de la Construcción (1959). El Plan Vial para los años 1959/1963 de la Provincia de Buenos Aires.

" Cámara Argentina de la Construcción ( $\mathrm{s} / \mathrm{f}$ ). Infraestructura portuaria en argentina 1810-2010. Recuperado de http://www.camarco.org.ar/File/ GetPublicFile?id=1207 (15/5/2019)

" Cámara de Diputados de la Provincia de Buenos Aires. Diario de Sesiones, Sesión del 21/1/1958. 
"Cámara de Senadores de la Provincia de Buenos Aires. Diario de Sesiones, Sesión del 2/5/1958.

" CEPAL (1959). El desarrollo económico de la Argentina. Análisis y proyecciones del desarrollo económico. Tomo V, México.

»Civitaresi, H. M. (2018). Caminos rurales, consorcios camineros y desarrollo regional en la provincia de Córdoba (Argentina) en la segunda mitad del siglo XX. Tiempo \& Economía, 5(2), 89-105. Recuperado de https://revistas.utadeo. edu.co/index.php/TyE/article/download/1359/1366/ (10/11/2018).

»Dirección de Vialidad de la Provincia de Buenos Aires (1959, agosto-septiembre). Vialidad $\mathrm{N}^{\circ} 8$.

"Dirección de Vialidad de la Provincia de Buenos Aires (1959, enero-marzo). Vialidad $\mathrm{N}^{\circ} 6$.

》Dirección Nacional de Vialidad (1961). Memoria 1959-1961.

"El Día (1959, octubre 5). La Plata.

»El Día (1961, octubre 5). La Plata.

》El Independiente (1958, agosto 25). General Alvear.

» El Tiempo (1953, enero 12). Pergamino.

»FAO (1954). Elementos del Bienestar Rural. Roma.

» Fernández, N. (2016). Políticas públicas, infraestructuras de comunicación e integración territorial en la provincia de Buenos Aires (1917-1943). VI Jornada de Becarios y Tesistas, Departamento de Ciencias Sociales, UNQ.

» Frondizi, A. (1965). El problema agrario argentino. Buenos Aires: Desarrollo.

» Gómez, T.y Tchordonkian, S. (2014). Redes viales y ferroviarias en las décadas del treinta y del cuarenta. Documento de Trabajo CESPA/FCE-UBA, 40. Recuperado de www.blogdelcespa.blogspot.com (8/8/2018).

" Gruschetzky, V. (2012). Saberes sin fronteras: la vialidad norteamericana como modelo de la Dirección Nacional de Vialidad, 1920-1940. En M. Plotkin y E. Zimmermann (Comps.), Los saberes del estado (185-211). Buenos Aires: Edhasa.

» Instituto de Planeamiento Regional y Urbano. Desarrollo del Municipio (1962). Cómo organiza su progreso un vecindario. Tomo I: Programa de Desarrollo Urbano y Rural a nivel municipal. Buenos Aires.

»Instituto Nacional de Estadísticas y Censos (1947). Cuarto Censo General de la Nación 1947.

» Instituto Nacional de Estadísticas y Censos (1960). Censo General de la Nación 1960.

» Iramain, L. (2013). Política económica en la dictadura. La orientación y calidad de la intervención económica del Estado en el sector vial. La actuación de la Dirección Nacional de Vialidad (DNV) (Argentina, 1976-1981). Documentos de Investigación Social UNSAM/IDAESS, 14, 1-41. Recuperado de https://www. unsam.edu.ar/institutos/idaes/docs/DoclS_24_Iramain.pdf(1/10/2018).

» Ivickas Magallán, M. (2017). Política, acción estatal y bienestar en el agro. Buenos aires (1958-1966). Historia Contemporánea 55, 637-668.

» Junta de Planificación Económica de la Provincia de Buenos Aires (1958, octubre-diciembre). Revista de Desarrollo Económico 1. La Plata. 
"Lacunza P. (2004). El nuevo papel del Estado en la Argentina peronista: Mercante y el Plan Trienal de Trabajos Públicos en la provincia de Buenos Aires (1947-1949). Anuario del Instituto de Historia Argentina 4, 101-126.

»Lázzaro, S. (2008). Estado, desarrollo y reforma agraria en la provincia de Buenos Aires (1958-1962). Anuario del Centro de Estudios Históricos «Prof. Carlos S. A. Segreti» 8, 85-106.

"Lázzaro, S. (2012). El desarrollismo y el problema agrario durante las décadas de 1950 y 1960. Secuencia 84, 127-160. Recuperado de http://secuencia.mora. edu.mx/index.php/Secuencia/article/view/1171/1061 (5/10/2018).

» Ministerio de Asuntos Agrarios de la Provincia de Buenos Aires (1961, enerofebrero). Asuntos Agrarios 89-90.

» Ministerio de Hacienda, Economía y Previsión de la Provincia de Buenos Aires (1952). Anuario Estadístico, 1944-1950. Buenos Aires.

» Ministerio de Obras Públicas de la Provincia de Buenos Aires (1963). Memoria de Obras y Servicios Públicos. Período 1-V-61 - 30-IX-63.

» Ministerio de Obras Públicas de la Provincia de Buenos Aires, Dirección de Vialidad (1963), Informe sobre el estado del Plan Vial al 31 de agosto de 1963.

" Ministerio de Obras Públicas de la Provincia de Buenos Aires, Dirección de Vialidad (1959). Mesa redonda sobre el Plan Vial de provincia de Buenos Aires. Años 1959-1963. Publicación № 7, La Plata.

" Ministerio de Obras Públicas de la Provincia de Buenos Aires, Dirección de Vialidad. (1960). Día del Camino. 5 de octubre de 1960.

" Ministerio de Obras Públicas de la Provincia de Buenos Aires, Dirección de Vialidad. Plan Vial 1959-1963. Tomos I y II.

» Ministerio de Obras Públicas, Dirección Nacional de Vialidad (1960). Conferencias sobre temas viales. Vol. 51, Buenos Aires.

»Muller, P. (2002) (Trad.). Las políticas públicas. Bogotá: Universidad Externado de Colombia.

»Ospital, M. S. (2002). Autos y caminos para la modernización de Argentina, 1920-1940. XVIII Jornadas de Historia Económica, Mendoza.

» Oszlak, O. y O’Donnell, G. (1981). Estado y políticas estatales en América Latina: Hacia una estrategia de investigación. Documentos CEDES/Clacso, 4. Recuperado de http://oscaroszlak.org.ar/articulos-esp.php (10/10/2018).

"Panella, C. (2014). Política bonaerense y gestiones gubernativas, 1943-2001. En O. Barreneche (Dir.), Historia de la provincia de Buenos Aires: del primer peronismo a la crisis de 2001 (89-116). Buenos Aires: UNIPE/Edhasa.

"Piglia, M. (2011). Gobierno provincial y clubes de automovilistas en torno a la elaboración y ejecución de la política vial en la provincia de Buenos Aires (19101943). En M. Ferrari y N. Quiroga (Comps.), Historias políticas de la provincia de Buenos Aires (85-114). La Plata: Instituto Cultural de la Provincia.

»Piglia, M. (2014). Autos, rutas y turismo: El Automóvil Club Argentino y el estado. Buenos Aires: Siglo XXI.

»Prebisch, R. (1955). Informe preliminar acerca de la situación económica. Buenos Aires.

»Primer Congreso Vial de la Provincia de Buenos Aires (1960). La Plata 5 y 6 de octubre de 1959. La Plata. 
"Raiter, A. et al. (2002). Representaciones sociales. Buenos Aires: Eudeba.

" Rougier, M. (2014). Economía y desempeño industrial. En O. Barreneche (Dir.), Historia de la provincia de Buenos Aires: del primer peronismo a la crisis de 2001 (116-145). Buenos Aires: UNIPE/Edhasa.

»Sabatier, P. (Ed.) (2010). Teorías del proceso de políticas públicas. Buenos Aires: Publicación del proyecto de Modernización del Estado.

"Salomón, A. (2017). Un lazo ausente: política vial y condiciones de vida en ámbitos rurales de la provincia de Buenos Aires (Argentina, 1940-1950). Revista Brasileira de História \& Ciências Sociais - RBHCS 9 (18), 16-35.

»Sikkink, K. (2009). El proyecto desarrollista en la Argentina y Brasil: Frondizi y Kubitschek. Buenos Aires: Siglo XXI.

» Tamayo Sáez, M. (1997). El análisis de las políticas públicas. En R. Bañón y E. Carrillo (comps.). La nueva Administración Pública. Madrid: Alianza Universidad. Recuperado de http://politicas.typepad.com/files/tamayo-saez_-el-analisisde-las-politicas-publicas.pdf (8/9/2018).

\section{Alejandra Laura Salomón / alejandralaurasalomon@gmail.com}

Profesora en Historia (Universidad de Buenos Aires), Magíster en Historia (Universidad Torcuato Di Tella) y Doctora en Ciencias Sociales y Humanidades (Universidad Nacional de Quilmes). Es Investigadora Adjunta del CONICET, Profesora Adjunta Ordinaria de grado y posgrado de la UNQ y miembro del Centro de Estudios de la Argentina Rural (CEAR/UNQ). Especialidades en la investigación: peronismo - bienestar social rural - políticas públicas - infraestructura rural - Argentina, mediados del siglo XX. 